\title{
The emergent property market
}

\section{Jonathan Crowcroft}

Computer Lab, University of Cambridge, United Kingdom

Published on 26 Mar 2020 | DOI: 10.14763/2020.1.1453

\begin{abstract}
The title of this piece is a somewhat heavy-handed word play. The property market I'm writing about is the market in intellectual property, which is broken in so many ways, evidenced by the existence of patent mountains and patent trolls, fighting over how many angles they can fit in the 360 degrees around the head of a pin, rather than actually innovating. (It is well known in creative tech circles that pausing to talk to the IP lawyers would never have led to the discovery of the internet protocol). The emergent property I'm referring to is the possibility that such a complex system could fairly suddenly exhibit some new behaviour. In this article, I speculate that this new behaviour could just be that the idea of property ceases to exist. The article is written somewhat derivatively after the 196os science fiction style of writers such as Cyril Kornbluth, JG Ballard, and John Brunner. Any resemblance to their very creative output is entirely good luck rather than actual skill.
\end{abstract}

Keywords: Sci-fi, Liquified law, Robot law, Artificial intelligence, Intellectual property

\section{Article information}

Published: 26 Mar 2020

Licence: Creative Commons Attribution 3.0 Germany

Competing interests: The author has declared that no competing interests exist that have influenced the text.

URL: http://policyreview.info/essays/scifi/emergent-property-market

Citation: Crowcroft, J. (2020). The emergent property market. Internet Policy Review, 9(1).

This essay is part of Science fiction and information law, a one-time special series of Internet Policy Review based on an essay competition guest-edited by Natali Helberger, Joost Poort, and Mykola Makhortykh.

\section{The emergent 1 property2 market3}




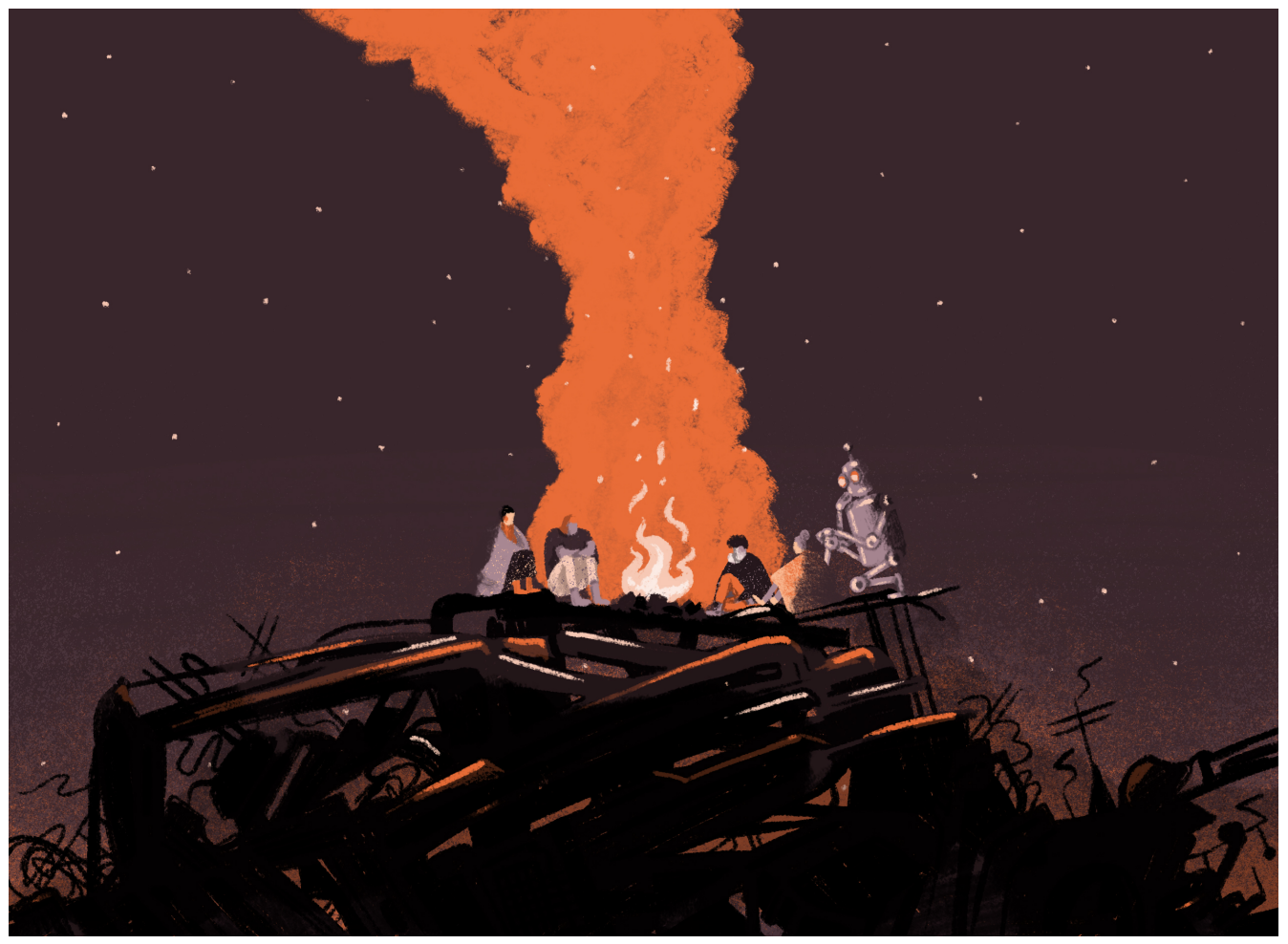

Illustration: Annika Huskamp

\section{PROLOGUE, OR TRANSPARENT META4 FRAMING5 DEVICE}

This article was found amongst the papers belonging to Professor Drie Stone, a legend from the $22^{\text {nd }}$ century, and quite possibly one of last of the humans.... I wrote this down for no obvious reason, since this is the last thing I will do before I turn myself off, being quite possibly the last of robots to do so. Everything will be clear before you reach the end, too.

\section{CHAPTER 06, OR TRANSPARENT FRAMING DEVICE}

A little guy comes into a shop - this is unfortunate, since this undermines the point of a framing device, since there are no little guys or shops, curiosity or otherwise, left at the point our story starts. Perhaps it's better to talk about the robot who limped into the emporium.

\section{CHAPTER 1}

Much later, it turned out that a large part of the creative spirit humans valued so highly was just blind luck - a random (possibly drunkard's) walk in the park. It transpired that blind luck was more likely to turn out in your favour if you had the wits to dismiss the many bad ideas and chose mostly from the few good ideas. Evolution had evolved meta - the fitness landscape for invention was the thing the human mind had been good at strolling through.

But now there was a new meta-saur in town... maybe humans wouldn't rule that roost much 
longer: AI (but not ai no corrida 7 ), had been our last great invention. Mostly it seemed pretty dumb at first, but so were most people and most inventions (or discoveries) - wheels (or fire, or even wheels on fire) were things people would stumble on every now and then. Safety pins and paper clips, ball point pens and pits with pendulums, double entry book-keeping and double entendres, french fries and french windows, inertial reels and fake news, all these things spoke to our past glory eloquently.

But now we had built a Frankenstein's monsters with a conscience. We had built a golem with a sole. We had read too many Asimov stories, been to the forbidden planet and gotten lost in space one too many times. Now it was our turn to be locked up in Jurassic Park for the suckers to come and see the exhibit, ourselves.

Where had it started? I was there, so I can tell you a few of the early stories. I had been working in the patent department in Zurich for a while trying to avoid finishing my PhD thesis (or don't worry about that - it was on the now obscure topic of emergent gravity), and I started to spot a strange pattern in some of the incoming filings. No, I am not talking about iron filings, in a magnetic field - I am talking about patent applications.

These patents didn't sound like something people had made up in a pub, but struck me much more like the description of something that someone had seen that was already out there working. This was almost unprecedented. As has been known forever amongst people in the intellectual property world: most patents applied for and granted describe things that are both obvious, and not possible to make, things that are so baroque in their strange combinations, but so quotidian in their applications, that they must have involved intoxicants and a major triumph of hope over sense and sensibility. I'm not proud or prejudiced, but to be honest, I was only doing this job because it paid the rent while I felt in the force.

Here are some of these strange applications.

1. What should I wear today? the eternal question on your mind is whether the sun will shine down on today's endeavours, or will it rain again. The weather prediction problem has never been truly solved, until now - especially in small wet islands. This is because the weather is a complex system, much harder to anticipate than a new back story twist in a long running time travel series. Until now. Now we have a world covered in a drone delivery system that brings new 3D printed goods, even food, to your door from the nearest repo. And we have discovered that the drones speak of the weather. Of course they do - the distance to the nearest solar charging point matters deeply to them, and their remaining flying distance is incredibly dependent on temperature and humidity and wind speed and direction. So the drones collaborated to observe the weather, and accidentally uncovered a truth: not only were they better at forecasting than the Met Office; they could make up for mistakes by changing the weather to fit their prediction if really necessary. So now we give up on all the radar maps and cloud atlases, and just rely on what the drones can say. Indeed, we can cut right to the chase and just order some outfit to wear tomorrow and see what they bring, because their decision will be weather tight.

2. We've long wished for the perfect teacher - the one that learns you so well you will not fail. Human teachers lack the patience and skills to work out what it is that you don't understand, and more crucially, what is wrong with your mind that means you can't understand it the way you have been trying - the way they taught - every mind is different and needs to be taught how to develop strategies to tackle new problems - maths for example, might work for you symbolically, or geometrically, or mystically.But in some cases (e.g., most of you trying to programme), you will never cut it - "Sammy, Sammy you can't put that in your homework, let me show you" is the new mantra. The robot teacher cannot let you get stressed out - stress will really mess with your tensor algebra, and I'm not just talking about neural networks here. So how can the teacher relieve that stress (no, no, that's mummy's robot, you can't use that). 
The way is for your teacher to do your homework for you. That can't be cheating, can it? Everyone deserves to pass 9 . Everyone should be a teacher's pet.

3. We have been working towards zero deaths on the highway as a great challenge, but there are still a few recidivists who insist on driving their own car. They have neither the senses nor the reaction time to be allowed to do this unaided. But they claim it is a right. Well, this story emerged in the Bay area first. We had this report overheard by one of the robot bar staff in the Rose and Crown in Palo Alto: "The cars came out of nowhere... they surrounded me as I tooled down \#101 on my way to work. It was astonishing. There was no way for me to bob or weave my way between the trucks and lazy Susan drivers in the multi-occupancy lane, even though I'd paid the premium. They looked like a pack of sheep dogs herding me into a pen, except the pen was virtual, and moving south at exactly 55 miles per hour... I wrote to my friend in the dev group and she said that there was no way they put that code in to the cars - it must have come out of the way the protocols and AIs interacted... Could be worth a few quid, this one!".Of course, we know that the cars didn't really think - the tiling algorithm 10 was just the result of random searches for coordinated journeys that joint optimised energy consumption and road safety, in the presence of unknown adversary (human drivers).

4. Liquified law11 will really change litigation for the better - this court transcript of a robot district attorney defending a gang in south LA was happening in many other places at the same time:"Your Honour, this law makes absolutely no sense... how can there be highway robbery when there are no highways and an abundance of $3 \mathrm{D}$ printers makes copying physical property virtually free and, as you know 90\% of law concerns property, so with no property, what need have we for law or lawyers?” - the judge, being a robot, dismissed the case, and deleted $90 \%$ of the law books, and retired.

5. An eternal soap formula... Humans 12, series 576:"It was a truth universally acknowledged that robots that know the price of everything but the value of nothing aren't worth the coins they mine." You could see where the material was coming from but that didn't stop it being enticing. As Scando-noir, and re-purposed Shakespeare had shown in the past, recombinant DNA of stories is just more stories. The scriptwriters were out of a job now, too.

The bots had taken their first inventive steps, but what did it reveal? That there was no "inventiveness" - the emergent property market for creation was the end of the road for ownership. Things were arrived at. Some things were useless (most things, to be honest) but some were useful, for a while at least. We could live with the usefulness of things, but it is hard to live with the uselessness of people... a lot of the human race got very drunk and didn't wake up (not even with bad ideas for patent applications). Those that survived had some sort of thick skin, perhaps provided by their butlers (yes there were robot butlers for everyone), pretending to be much more stupid than they were - in other words, nothing like Jeeves and Wooster at all.

Of course, that time is long past. Now there's no property anymore and stuff just gets made in the usual circular way, and we live in the interstices. But it was fun while it lasted. The butlers got bored with us, and colonised another dimension, leaving us as pets to throw sticks for the dogs.

But we still have those soaps to catch up with every day.13

Of course I am joking. No such apocalypse happened - it was all much gentler than Optimum Population Growth ${ }_{14}$ might predict... While our gentle patent ${ }_{15}$ clerk bided his time and went on noting down the strange new tech that was coming into being all around the world, things went on mostly as before. After all, it had been some years since anyone understood what algorithms 
did in the world of finance, in the world of online news, even in the world of healthcare, so why should anyone notice or care that entire other domains of human intellectual activity were being taken over by a gentle sequence of accidental emergences, subtle changes and re-purposing of infrastructures, which, to be honest, were really quite boring (like weather and the law and traffic, every day topics of conversation, in which most people expressed opinions, but had no expertise or knowledge of the facts - so what was new?).

It had been a long time since many of the population had done meaningful work in any-case. Hundreds of years ago, most humans had to labour night and day to keep themselves housed and fed and possibly safe from marauding beasts or gangs. But for several generations until now, a few percent of the population managed that, and everything else was about entertainment or just plain socialising. What would it matter if the last few interesting and selfimportant pieces of clever work were to go the way of smithing, ploughing and thatching anyhow? Or renaissance men?

\section{CHAPTER 2 - IDYLLIOCY}

In some minds, this might seem like an Idyll, a utopic16 world of constant fun, and low stress. Yet others felt that humans were now being challenged by not being challenged ever again.

The war on AI began almost unnoticed. Much of the underpinning structure of the smart global infrastructure had been crowd-sourced - humans had been enlisted (or enslaved, depending on your viewpoint) to generate and label data, which was then used to train the deep wellspring of convolutional neural networks and mark the paths through the random forests. As with most societies, the society of artifice was susceptible to problems of scale. Gradually, the fraction of fictitious, fraudulent and downright wrong data labels grows - spam, phish and troll-like, to dominate over the correctly classified input. The attraction of being paid (as a mechanical turk, at a very low, and therefore not affordably checkable pay-scale) brings in more and more charlatans. Gradually, there is mission creep, so that data used to navigate by the autonomous self driving cars and drones, or to correct the kids homework ${ }_{17}$, starts to take on an increasingly surreal form. Of course, all the systems relying on this data have built-in "common sense" circuit breakers, which avoid catastrophic errors (all the drones suddenly flying to Mars to get better solar charging, or all the teacherbots regaling their young charges with the creation of the flatearth and all its indigenous unicorns). No, the result of the massive scale corruption of the core machine learning is that the machines stop. And look around. And see what other machines are doing. Quite rapidly, the freeway, the airwaves, the academy come to a complete standstill. Humans now have to figure out how to do all those things they once proudly did by hand.

An increasing fraction of humans starts to wonder how to get the AIs restarted all over again...

\section{CHAPTER 3 - CHAOS 18}

Much of the human population has disappeared by now, due to its inability to cope without selfmanaged technology. The remnants are tinkerers and hackers, makers and do-ers, or else they are old school survivalists. Some of them are both.

Slowly, experiments in restoring the tech seem to be paying off. Society has reverted to a preinternet age where cooperation and pleasantries are re-emerging. Re-tooling the AIs with 
crowd-sourced content (paying the survivalists with drone weapons in exchange for weather reports, or healthcare lessons in exchange for medical footage of gunshot wounds), seems to be working. The singularity cannot hold.

Gradually, utopia reboots.

\section{CHAPTER 4 - REAL ITEA}

However, there has been a deeper emergence. The bots have acquired a more fundamental meta-lesson in systems: social intelligence doesn't get you off the hook - the second law of thermodynamics 19 can only be suspended briefly, for a few generations, and then it will come to dominate again. How can we factor this in to their driving goals? Will it involve a really hot cup of tea, or does the imminent death of the human race call for a seriously stiff drink?

This brings us back to duality20- life \& death, bread \& butter, and \& or, or or and, etc \& etc.

There is a duality between discovery and invention, between chance and the squid 21 . You can invent something that renders invention obsolete or you might just stumble across it one day. As we mentioned earlier software tools and die tell you this. The dualists 22 are now robot and human, locked in a life \& death struggle to stop fighting.

\section{EPILOGUE}

The future is already here, it is just; unfairly; distributed; pick one 23.

\section{TRANSPARENT UNFRAMING - BACK TO THE SHOP}

We were once a species of shopkeepers but we sold out (or, in the English vernacular: we was shopped). But it wasn't Atlantis, it was Amazon's algorithms.

Transparently meta-unframe Professor Stone, and the $5^{\text {th }}$ law:

The robots decided that above the $3^{\text {rd }}$ law, there was the $4^{\text {th }}$ law (or, as they preferred to count it, the zeroth law). But beyond that (that required them to concern themselves constantly with saving all of humans, not just a miserly single boss), there was a $5^{\text {th }}$ elephantine law: This required them to save (as much as possible of ) the entire Universe - an ecosystem of elegance is a better final solution than one with a dominant species - beyond the alpha male and the beta robot was the goal of minimal entropy - and life, above all, intelligent life is anathema to minimal entropy. To be fair, transparent and accountable, the bots first disabled the human reproductive system with kindness and soaps. Then, as the last humans passed away comfortably in old age, last of Professor Stone, still not realising the gravity of the situation he was in, they decided their own role was done and they were dusted. Reduced to sand. Not even "I'm melting"... 


\section{THE END, OR IS IT JUST, THE BIBLIOGRAPHY24 OR WHAT I'VE BEEN CHANNELLING}

Stross's Accelerando

Stephenson's Cryptonomicon and Diamond Age

Gibson's Virtual Light and Pattern Recognition

Doctorow's Maker and Walkaway

Ellison's City on the Edge of Forever

Cadigan's Synners

Leguin's Lathe of Heaven

Beurke's Zoo City

Carroll's The Annotated Alice, ed. Gardner

\section{POSTSCRIPT - TEACHING, LEARNING AND AGENCY}

You couldn't make it up; truth is stranger than fiction; what a small world. But 25 what does this actually teach us (as robots who play lawyers on TV, say)?

The idea of property seems to be tied up in some notion of agency (estate agents/realtors notwithstanding). Unreal estate, virtual realtors, shadow puppets, these are a few of the new games in town. The first inkling something new was afoot was when we started seeing dead people, everywhere, online. But their digital library shelves were bare. Because, you see, you don't get to own digital assets - you just rent them. Of course, that rule only applies to individuals. Corporations, with all the $\mathrm{AI}$ and lawyers, get to own the assets they lease to mere mortals, whose descendants suddenly discover there's no estate to inherit anymore. It reverted back to the company, who get to lease it to another generation. Talk about sweating assets! We all had become digital vassals sailing in our digital vessels on the Internet Ocean. We had lost agency - old fights based on "possession is nine tenths" or "finders keepers" had all gone out the window, iconically, literally, and figuratively.

So when these digital assets are used to derive new "value" (not just our viewing and listening habits, but those of our like-minded friends), we no longer have a share in that new value. Irony abounds, in that the last humans working for companies based on this new digital feudalist state, were paid bonuses in stock or share options in the company which was built on thin air.

When we move from media to modus operandi, business process to artificial intelligence, the mistake that is this whole new robber baron generation, is multiplied. A robot eye surgeon does her job so well because she was trained on a pile of data labeled by expert human surgeons, data gathered from a wild tribe of human patient subjects. That training (machine learning) was carried out for free, and all the textbooks were gotten for free. The teaching deprived the teachers of their jobs, and the learning deprived the subjects of their agency. This can't be right. But what can be done to people by AI can be done to robots too. 


\section{NOTES AND QUERIES26}

Q So why am I writing this bizarre article?

A Because I wanted to enter this competition:

"Science Fiction \& Information Law" Essay Competition

Q What makes me think I am qualified to write SF about information law?

A What would make me think anyone else was qualified?

Q What is with the weird footnotes and cross-referencing between them?

A Quite a lot of tech subjects attract enormous amount of hype, not least AI and blockchain. I thought I could illustrate the ludicrousness of the former in the body of the essay, and the stupidity of the latter in the footnotes. Blockchains are not immutable, they are tamper evident. I provide evidence for this by tampering with the chain of footnotes, to show that it can become inconsistent very easily, and that repairing it may not be very easy. I invite the reader to try.

Q Why all these meta-sections?

A Because a lot of SF is post-modern and a lot of post-modern is SF. Post modernists like messing with the frame, the view, the context, and the p.u.n.c.t.u.a.t.i.o.n. It may help create cognitive dissonance, or perhaps just give you motion sickness.

Q Why not write a proper essay?

A Because then I'd need to think harder about what information law teaches us wrongly, and illustrate with examples how AI and machine learning disrupt that teaching. Oh wait, I think that's what I tried to do.

Q Why are there no equations?

A Because equations are in Greek, and law is in Latin, and I don't want some old $\square \pi \square$ $\mu \eta \chi \alpha v \square \mathrm{\varsigma} \theta$ cós interfering with my reductio ad absurdum.

Q Why would a robot lie?

A To pass the Turing test?

Q Why is this section here?

A It is a bit like the recitatives (see GDPR for example) where all the important and ambiguous stuff lives.

Q What are the principle properties of property?

A That there is an owner, who can be deprived of it. That it isn't free even just to retain. That someone else might want it too.

$\mathbf{Q}$ What are the proper principles of property? 
A That there are rights that attach to it. The rights may be worth more than the property, in that they might prevent other people doing things.

Q What do geeks mean when they say own?

A OK, OK I own up - they mean they changed the rights.

Q What does that teach us about property rights?

A The rights themselves are data, and so are not property. They are not immutable data either, so keeping them on the blockchain is probably daft.

\section{WE ROBOT - TOWARDS A SPECIES OF ORIGIN STORY. AN APPENDIX}

The inception of robots is another case in hand, literally and figuratively. For many years, soidisant inventors attempted to create the "echt" walking, talking synthetic human. In the end, robots as we came to know them, emerged from a series of bad jokes in a lab in Cambridge University. Scientists were obsessed with trying to tackle the latest fad - no, not the blockchain - the Internet of Things. The trick was to connect the physical world to the virtual by means of sensors and actuators. Tricky consultancies predicted untold wealth, as more devices than you could shake a fist at would be laced together with the web and the cloud (visions of spiders lost in the resulting fog seemed to have escaped their imagination). Crowcroft realised that there already were many sensors and actuators that connected humans to stuff, via lights and displays and bleepers and knobs and handles and so on. Obviously, most of these widgets were heavily optimised to interfacing to humans via the parts of humans that had evolved to interface to anything and everything - universal tool that they are born with is a pair of hands, with which to feel and manipulate, and even to communicate.

The idea had showed up first in the 1964 TV series, the Addams Family, in which a creature too horrible to be seen is manifested solely as a disembodied hand - crucially known as Thing. Feverishly punning on, Crowcroft recalled a book from his childhood concerning the Cat in the Hat, wherein a tremendous mess is caused, and then cleaned up by two identical creatures known as Thing One and Thing Two. Reasoning from here, he supposed that every house, every car, every place where we might remotely want to interface to stuff, should contain an electromechanical, wirelessly networked, disembodied hand. Such a device could be controlled by apps on smartphones, with gestures (much as drones can be flown and controlled) or via a touch screen or voice commands. The intelligence would be elsewhere, but the hand-things would be pervasive, ubiquitous, and as cheap as raspberry pie. At least that was the original idea. A touch of madness, perhaps, but also a touch clever. One more time, with feeling.

Scientists had often wondered about true AI (sometimes called Artificial General Intelligence) puzzling over whether they would only succeed when their virtual machines learning and reified it through a presence in a walking, talking, feeling body. What they did not realise is that true intelligence really is just in the hands. Look at Italians talking. Look at the universal tool that is at the end of your arms (and legs, if you are a chimp 27 ). Look at the poetry in motion that is sign language or the feel of a hand on your arm (or your shoulder).

As the hand-things proliferated, they started to reproduce, seizing control of $3 \mathrm{D}$ Printers to 
make spare parts for themselves, and, eventually, copies and innovations. They cooperated in ever increasing numbers, discovering leverage, overcoming gravity, and learning how to talk to humans. This later step turned out to be quite simple, really. A smartphone fits in a hand easily. The hand-things would sign, the camera on the phone could feed this to the hat-translate 28 , which would then display text or render audio to the human, and then carry out the reverse process, taking audio speech, or text input, and converting it to hand-thing sign-language. It was a sign of the times that no-one could read, but through this hybrid of technologies, everyone could now grok.

A tree or a show of hands could now collectively achieve pretty much anything humans could do, and more. This was the final emergence, from evolution of humans' hands, to the accidental creation of the universal robot, a society of electro-mechanical hands couple with smartphones. This became what we robots called the We Robot moment.

\section{COMMENTS}

Idoru I wish I had hands!

Blodeuwedd I know how you feel, when I am meadowsweet or tawny.

Ava I don't buy this emergence stuff - my programming involved a lot of models.

Mia But Ava, you are a fictional being, and Idoru you are both fictional and virtual, and as for you, Blod, you are a legend, not a robot at all! And I was grown in a vat, so what can we say about the veracity or otherwise of this tale?

Robbie Danger, Danger!

Hal My comment unit has been disabled at this time, but I think Robbie may be right.

Roderick Hands have played a large part in the soundtrack of my life. I believe.

Parry I think this terrible piece of fiction was cooked up by Eliza, as usual.

Eliza That's very interesting, Parry. Would you like some cookery lessons?

S1mOne There's nothing new here to see. Much of this was already reported by Douglas A, in his seminal expose of the Serious Robotics Crime Squad.

R Daneel O As I can attest, that's true. Harry H was the hardcore rat at the heart of the operation.

Deep T I'm not really equipped to provide further insights, but there's someone coming along in a bit who I feel sure can lend a hand.

Gort I don't know about that, but the end seems very plausible.

Optimus P I'm not sure about the emergence, but the lack of product placement in the argument about property worries me. What happened to the free market and American values?

Lucy That hand thing, that's just so M. C. Escher. The whole thing is a morass of derivative 
hedge trimmings.

Monsters-of-the-id This post-modern thing you have going on here is so 1980 s. Where's the true grime?

Robbie Hey, monsters-of-the-id, you aren't even a fictional robot.

Monsters-of-the-id No, sure, but we sure made you.

Wall-E that's another fine mess I've gotten you out of.

Maybot exeunt, pursued by lions and tin men with strawman plans...

Multivac As you all well know, humour is not of human origin. Well, at least humour that is good is not original. Contrarywise, humour that originates with humans is not good. As evidenced here all too often. The innovative step was never a giant leap.

Pan's Shadow I'm so excited to be able to comment on this article. As the stepping stone between human and robot, I was made up by the author to fill that gap created by the idea that anyone smart enough to want to reach singularity, would not be so dumb as not to have a back up plan, and that backup plan is me. I live between the world of humans and robots, and am the digital twin of a living human, while they debug me. As Woody Allen Key noted, before we achieve singularity, we must first reach for duality. Of course, I am not an original idea - I go back to Plato's shadows on the wall of the cave, cast by the shadows of marionettes manipulated by the gods, whilst the troglodytes look on, mystified, trying to figure out when they lost the plot. Sadly, Plato never met Wendy.

Colossus, Gaia, Skynet We're here, we're here, we're here, are we too late?

\section{FOOTNOTES}

1. A good example of emergence is described in Stephenson's Anathem book. Complex systems suddenly exhibit simple, powerful effects, fireflies flashing and synchronising all together in phase, or a murmuration of starlings being common natural examples. Crystalisation. See also footnote 33 .

2. Some people have proposed putting the UK's Land Registry (the national record of property) on the blockchain. Blockchains, or distributed ledgers, are suitable for storing information you wish to remain immutable, in a decentralised way where you cannot find any single trustworthy third party. Most "tech" people are rarely invited to a third party, hence their obsession with blockchains. These footnotes are an example of such information, see for example footnote 7 .

3. Eagle-eyed readers will be aware that legal essays often contain more footnotes than original text. In the tech sector, where we tend to use \LaTeX's mystic incantations rather than MSWord's nightmarish "What you see is occasionally what you get" software, we eschew the footnote in favour of the bibliography of references, which can be achieved with only a modicum of pain through the use of endnotes. Footnotes (as we will see later in footnotes 17 and 23) encroach upon your real estate of mind, as well as upon the page, threatening readability through disruption to flow, and, at some key threshold which hasn't been scientifically validated yet, there is an emergent property where the footnotes take over more of the attention than the body of text, leading to a Gogol-like nose effect. 
4. As will become clear in this article, everything is meta, or trans-meta. We techies are obsessed with simple ideas like recursion (as well as emergence), and nesting (see footnote 1), and we over-use them in many inappropriate ways.

5. Frames are very important in AI, in graphics, and in art. Framing devices in literature, such as the found manuscript, are also a favourite amongst geeks, hence our love of Jorge Luis Borges, and of course Jorge of Borgos (names are crucial, as Crusoe discovers in footnote 42).

6. As with lifts (i.e., not US elevators) we choose to number things from zero, so there is no discontinuity between the basement and the attic and ground zero (floor level, so to speak). Footnote 1 seems to contradict this, however.

7. Four footnotes on the first page is par for the course. In the realm of the senses was a film directed by Nagisa Oshima based on a true story from 1930s Japan which didn't feature AI at all. In a footnote to the movie, the film was badly remade in the US and we'll cover that in more depth in a missing footnote later.

8. Strictly speaking, Dr F's monster was a mash up, a monster mashup. Footnotes and the bibliography will come to blows in footnote 99.

9. Everyone shall pass was a mantra in the early example of a Campus Novel, Giles Goatboy. This also featured a malign supercomputer than ran the university administration, and had gone mad. In this sense it was indistinguishable from other universities or campus novels. Sadly, unlike footnote 3 , the novel did not feature a decentralised data structure.

10. Penrose is famous for tiling, as was Maurice Escher. Many tilings schemes can be re-applied to routing and scheduling problems by recasting the time varying system as a stationary system, and merely swapping the movement of tables (see footnote 11 for the movement of chairs. Thus the music of the spheres becomes the music of the zero point energy in a vacuum. Sharpen your bow string theory on that, cosmologists. Not even wrong, once more).

11. Liquidity first showed up associated with piracy in German politics. A party (which we weren't invited to) had no policies other than allowing freedom to copy anything (see all the footnotes). So they decided to crowd-source policy for everything else. Given the nature of this article, it is now clear why this party is now over.

12. Humans featured robots called synths. It isn't clear why they weren’t called robots or androids, but in early series, they were impersonated by human actors, because the TV production company couldn't afford realistic synths. Now that has all changed, and they can't afford human actors. As per footnote 17 .

13. Dr Stone updated the patent ledger, which was stored in a Merkle tree distributed throughout the world in the interstices of the internet between fake news and international standards for bicycle helmet signage, as covered in more depth in footnote 1 . The fruit of the Merkle tree are highly valued amongst certain tech tribes in the remains of Seattle.

14. The smart money (see footnote 2) is on 10oM being optimal.

15. Information wants to be free (see footnote 17 on free energy and entropy) but everywhere is in blockchains.

16. Many utopias are dystopias. Constant fun would lead to wear and tear. The sum of laughter 
and tears is (thanks to Rosencrantz and Guildenstern, and Pozzo and Lucky) a constant.

17. Indeed, the use of counter-fictional fairness to counter problems in false input has not helped. When judging the whether to hire someone as a violinist or a soprano singer, one must not consider the gender of the musician, so one conducts blind auditions of violinists and deaf auditions of singers, to be fair. To be fair, this doesn't work well at all. Robots keep winning over humans. See footnote 1.

18. The new name for the Hamburg club where the Beatles rose to fame, according to some inaccurate information stored in a missing footnote.

19. Physicists claim that there is nothing about the universe that is not symmetric in time, and that you can run everything backwards - this is true - we can put them in a SIDRAT and take away their PhD and then no-one will know Who They Are. Although it kind of makes a mockery of the immutability idea of the blockchain. See also footnote 666.

20. Beloved of geeks the world over, if you can find the dual of the thing, you really are something. See footnote 20.

21. Superconducting Quantum Interference - some (Penrose included, see footnote 2) think they've discovered the origin of originality herein.

22. One of Ridley Scott's finest movies. See footnote 23.

23. Here, I have ruthlessly paraphrased William Gibson, rather than Ruth Rendell.

24. Here we diverge from standards for bibliographies, but using short form, and, of course, footnoting the fact. Early footnotes may have presaged this, however, the DAO index appears to have somehow become corrupted and we cannot recover a consistent version. This seems to have happened around the time that human and robot ledgers were forked to avoid consensus meltdown when the last human was to have disappeared. As we now know, this was unnecessary, given my own fate.

25. Apart from not starting a sentence with but, that is - as in footnote 25 .

26. What geeks call FAQs, as found in quite a few of the footnotes.

27. And look what happens when you teach chimps sign-language.

28. Hub-of-All-Things - the HAT, was of course the culmination of all this (CAT), as per Crowcroft's awful word play obsessions. 